\title{
Noninvasive assessment of autonomic activity for evaluation of pain in calves, using surgical castration as a model
}

\author{
M. Stewart, ${ }^{* 1}$ G. A. Verkerk, $†$ K. J. Stafford, $\ddagger$ A. L. Schaefer,§ and J. R. Webster* \\ ${ }^{*}$ AgResearch Ltd., Private Bag 3123, Hamilton 3240, New Zealand \\ †DairyNZ, Private Bag 3221, Hamilton 3240, New Zealand \\ ¥Massey University, Private Bag 11222, Palmerston North 4442, New Zealand \\ §Agriculture and Agri-Food Canada, Lacombe Research Centre, 6000 C \& E Trail, Lacombe, Alberta, Canada T4L 1W1
}

\begin{abstract}
The role of the autonomic nervous system (ANS) in mediating eye temperature responses during painful procedures was examined in thirty 4-mo-old bull calves randomly assigned to 4 treatments: 1 ) sham handling control $(\mathrm{C} ; \mathrm{n}=8), 2)$ surgical castration $(\mathrm{SC} ; \mathrm{n}=6)$, 3) local anesthesia with sham handling (LAC; $n=8)$, and 4) local anesthesia with surgical castration (LASC; $\mathrm{n}=8)$. Maximum eye temperature $\left({ }^{\circ} \mathrm{C}\right)$, measured by infrared thermography, heart rate (HR), and heart rate variability (HRV) were recorded continuously from 25 min before to 20 min after castration. The HRV was analyzed by examining segments of 512 interbeat intervals before and after treatments and comparing the root mean square of successive differences (RMSSD), high and low frequency (HF and LF, respectively) power, and the ratio of LF and HF powers (LF:HF). Jugular blood samples were analyzed for norepinephrine and epinephrine in $\mathrm{C}$ and $\mathrm{SC}$ treatments and for cortisol during all treatments. There was an immediate increase in HR following castration in $\mathrm{SC}(+15.3 \pm 2.8$ beats $/ \mathrm{min})$ and LASC $(+6.3 \pm 2.4$ beats $/ \mathrm{min})$ calves. Eye temperature increased during the 20-min observation period in $\mathrm{SC}$ and LASC calves $\left(+0.47 \pm 0.05^{\circ} \mathrm{C}\right.$ and $+0.28 \pm 0.05^{\circ} \mathrm{C}$, respectively), and there was a small increase in $\mathrm{C}$ calves $\left(+0.10 \pm 0.05^{\circ} \mathrm{C}\right)$. Following castration in $\mathrm{SC}$ calves, there was an increase in RMSSD $(+25.8 \pm 6.4)$ and HF power $(+11.0 \pm 6.5)$ and LF:HF decreased $(-2.1$ $\pm 0.7)$. Following castration in LASC, there was an increase in RMSSD $(+18.1 \pm 4.9)$ and a decrease in LF power $(-10.2 \pm 5.0)$. Cortisol increased above baseline within 15 min following treatment in both castrated groups, but was greater for SC calves $(+18.4 \pm 2.3$ $\mathrm{ng} / \mathrm{mL})$ than for LASC calves $(+11.1 \pm 1.9 \mathrm{ng} / \mathrm{mL})$. After castration, norepinephrine increased 3 -fold and epinephrine increased by half in SC calves but not in $\mathrm{C}$ calves. There were no changes in HR, HRV, or cortisol responses to $\mathrm{C}$ or LAC treatments. Local anesthetic
\end{abstract}

Received January 26, 2010.

Accepted April 30, 2010.

${ }^{1}$ Corresponding author: mairi.stewart@agresearch.co.nz reduced, but did not eliminate, responses to surgical castration. The synchronized increase in catecholamine and HR responses immediately following SC treatment suggests the initial response was mediated by the sympathetic branch of the ANS. The subsequent changes in RMSSD, HF power, and LF:HF ratio indicated this was followed by an increase in parasympathetic activity. The use of HR, HRV, and infrared thermography measurements together provide a noninvasive means to assess ANS responses as indicators of acute pain in cattle.

Key words: castration, eye temperature, heart rate variability, catecholamine

\section{INTRODUCTION}

Acute responses to noxious stimuli include activation of the autonomic nervous system (ANS) and hypothalamic-pituitary-adrenal (HPA) axis. These 2 physiological systems respond to mediate the stress response and restore metabolic homeostasis. Acute pain and fright activates the sympathetic division of the ANS to release catecholamines from the adrenal medulla as part of the "fight or flight" reaction. The brief, early phase of this activation is difficult to measure. In contrast, the cortisol response that is mediated by the HPA axis has a slower onset, is more persistent, and is easily measured. Increases in HPA activity (i.e., cortisol levels) in response to painful husbandry procedures in calves have been well documented (Stafford and Mellor, 2005a, b); however, less attention has been given to measuring ANS responses to pain in cattle. Methods used to measure sympathetic nervous system (SNS) activity include heart rate variability (HRV), eye pupil diameter, skin resistance, peripheral blood flow, and plasma catecholamine concentrations. Catecholamines promote energy mobilization, blood vessel dilation, and increased muscle contractility and alter cardiac output, respiratory rate, and other responses required for the rapid fight or flight response.

Relatively few studies have measured catecholamines in farm animals. This may be because of practical difficulties in sample collection and processing, associated 
with catecholamines' low concentrations and short half life (1 to $2 \mathrm{~min}$ ) in plasma (Hjemdahl, 1993), as well as the high cost of the assay techniques. Increased catecholamine concentrations were found in response to branding (Lay et al., 1992a,b), isolation (Lefcourt and Elsasser, 1995), simulated transport (Locatelli et al., 1989), and dehorning in cattle and ring castration and tailing (Mellor et al., 2002) and transport (Parrott et al., 1994) in sheep. No published studies have measured acute changes in catecholamines following castration of calves.

Recently, it was suggested that the temperature of the eye in the region of the lachrymal caruncle, when measured by infrared thermography, may be a practical, noninvasive means to measure SNS activity in cattle (Stewart et al., 2008, 2009). A decrease in eye temperature observed following disbudding of calves without local anesthetic was attributed to sympathetically mediated alterations in blood flow in capillary beds (Stewart et al., 2008). This hypothesis was supported by the synchronized changes in HRV associated with an increase in SNS activity. Further investigation of the role of the ANS in regulating the eye temperature response is required for understanding the underlying mechanisms. The present study investigated changes in ANS activity and eye temperature responses using surgical castration of calves as the model of pain.

Castration of calves is a common husbandry practice used by farmers to modify temperament, prevent unwanted breeding, and alter carcass quality. Pain alleviation following different methods of castration was reviewed (Stafford and Mellor, 2005b). Surgical castration caused a greater acute pain response than other castration methods, but healing was faster with less chronic pain (Molony et al., 1995; Stafford and Mellor, 2005b). This makes it a suitable model to assess acute ANS responses to pain. In cattle, the effects of surgical castration on growth and feed intake (Fisher et al., 1996), heart rate (Schwartzkopf-Genswein et al., 2005), cortisol concentrations (Stafford and Mellor, 2005b), and behavior (Molony et al., 1995; Schwartzkopf-Genswein et al., 2005) were investigated. The aim was to examine the role of the ANS in mediating the eye temperature response during a painful procedure by measuring eye temperature, heart rate (HR), HRV, and catecholamine responses following surgical castration of calves.

\section{MATERIALS AND METHODS}

\section{Animals and Treatments}

The protocol and conduct of this study were approved by the Ruakura Animal Ethics Committee (Hamilton,
New Zealand). A total of thirty 4-mo-old Friesian bull calves with a BW of $106 \pm 3 \mathrm{~kg}$, managed outdoors in a pasture-based system, were used. Calves were habituated to intensive handling and the holding facilities used for $3 \mathrm{wk}$ before the start of the trial. Calves were habituated to restraint in the calf squeeze chute where the surgery would occur and to wearing HR monitors. The trial was conducted over 8 d, with 3 to 5 calves sampled each day, one at a time. The day before treatment, hair was clipped from the thorax immediately behind the right leg, to allow maximum contact for the HR monitors, and an indwelling jugular catheter was inserted. The same veterinarian undertook all castration procedures.

Calves were assigned randomly to 1 of 4 treatments.

1. Control $(\mathbf{C} ; \mathrm{n}=8)$ : scrotum and testes were handled to simulate cleaning and administration of local anesthetic (without needle insertion) for the time normally required for administration (approximately $1.5 \mathrm{~min}$ ) and again $10 \mathrm{~min}$ later to simulate the castration procedure (approximately $1.5 \mathrm{~min}$ ).

2. Surgical castration ( $\mathbf{S C} ; \mathrm{n}=6)$ : scrotum and testes were initially handled as described for C. Ten minutes later, the testes were exteriorized by an incision across the base of the scrotum. Gentle traction was applied to each testis singly until the spermatic cord broke.

3. Local anesthesia control (LAC; $\mathrm{n}=8)$ : after cleaning, $5 \mathrm{~mL}$ of $2 \%$ lignocaine hydrochloride (Lopaine, Ethical Agents Ltd, Auckland, New Zealand) was injected into each testicle through the distal pole and into the distal end of the scrotum followed by a subcutaneous infiltration $(7 \mathrm{~mL})$ at the neck of the scrotum (Weaver et al., 2005). Ten minutes later, the scrotum and testes were handled to simulate the castration procedure as described for C.

4. Local anesthesia plus surgical castration (LASC; $\mathrm{n}=8$ ): lignocaine hydrochloride was administered as described for LAC, followed 10 min later by a prick test (to skin at the base of the scrotum) to ensure absence of skin sensation before proceeding with surgical castration as described for SC. Analgesia was confirmed by the absence of a behavioral response to the prick test; this criteria was met at $10 \mathrm{~min}$ in all animals.

Each day, scheduled calves were brought into a holding pen $(3.1 \times 2.8 \mathrm{~m})$ adjacent to the sampling area that had access to straw bedding, hay, and water. Calves were allowed $1 \mathrm{~h}$ to settle before sampling started. Approximately 15 min before sampling, each calf was fitted 
with a HR monitor and moved into the restraint chute, where it remained for the 45-min sampling period. After a 10-min period for baseline data collection, the calf was subjected to its allocated treatment manipulations. The mean time interval for administration of anesthetic or sham handling was 1:37 \pm 0:26 min:s and for the castration or sham procedure was 1:43 \pm 0:25 min:s. Posttreatment responses were monitored for a further $20 \mathrm{~min}$. Cardiac activity and eye temperature were recorded and blood samples were collected throughout the 45-min procedure for each calf.

\section{Infrared Thermography}

An infrared thermography camera (ThermaCam S60, FLIR Systems AB, Danderyd, Sweden) was used to collect images of the eye during the 45-min sampling period. All images were collected from the left side of the calf (approximate distance: $0.5 \mathrm{~m}$ ) at a right angle. Maximum temperature $\left({ }^{\circ} \mathrm{C}\right)$ of the medial posterior palpebral border of the lower eyelid and the lacrimal caruncle (Stewart et al., 2008) from each image was recorded manually approximately every $20 \mathrm{~s}$. Continuous recordings of eye temperature during the sampling period were captured via a fire-wire cable connecting the infrared camera to a laptop. Image analysis software (ThermaCam Researcher 2.7, FLIR Systems AB) was then used to determine eye temperature when manual recording was not possible during short periods when the calves moved their heads. Ambient temperature $\left({ }^{\circ} \mathrm{C}\right)$ and relative humidity $(\%)$ inside the sampling area were recorded every $30 \mathrm{~min}$ and used to calibrate the camera for atmospheric conditions.

\section{$H R$ and HRV}

Continuous interbeat intervals (IBI) were recorded using Polar HR monitors (S810i, Polar Electro Öy, Helsinki, Finland). These monitors were attached to a strap placed firmly around the thorax, over the previously clipped area, and ultrasound transmission gel was applied at each electrode contact point to increase conductivity. The stored data were downloaded via a serial interface to a computer for analysis. Time domain measures analyzed were mean $\mathrm{HR}$, the time interval between consecutive beats ( $\mathrm{R}-\mathrm{R}$ interval, the inverse measure of HR), and root mean square of successive differences (RMSSD). Frequency domain measures analyzed were high frequency power (HF; 0.30 to 0.80 $\mathrm{Hz})$, low frequency power ( $\mathbf{L F} ; 0.04$ to $0.30 \mathrm{~Hz})$, and the LF:HF ratio; these were calculated by fast Fourier transformation using HRV software (Niskanen et al., 2004). To fulfill recommendations for analysis of HRV using fast Fourier transformation (Task Force of the
European Society of Cardiology, North American Society of Pacing and Electrophysiology, 1996; von Borell et al., 2007), short segments of data containing 512 beats were examined. Frequency band widths were selected with consideration for the respiratory frequency of calves, and the HF and LF power were presented as normalized units to account for interindividual differences. Normalized units represent the relative value of each power component in proportion to the total power minus the very low frequency component (frequencies lower than the lower limit of the LF band). Continuous recordings of IBI data are prone to measurement errors (Marchant-Forde et al., 2004); therefore, before analysis, a function within the Polar software (Polar Precision Performance Software; version 4.03, Polar Electro Öy) was used to correct for artifacts (e.g., ectopic heartbeats). Only data sets with an error rate of less than $5 \%$ were included in the analysis. Six individual IBI pools were removed because of this higher error rate; these deletions were evenly distributed throughout the LAC, LASC, and SC treatments.

\section{Blood Sampling and Assays}

To enable blood sampling every $30 \mathrm{~s}$ so that the anticipated acute changes in catecholamine concentrations could be detected, continuous blood samples of $6 \mathrm{~mL}(12 \mathrm{~mL} / \mathrm{min})$ were collected via jugular catheter attached with silicone tubing to a peristaltic pump into prechilled EDTA tubes (placed on ice) from -2 to 10 min relative to the time of castration (time $=0 \mathrm{~min}$ ). For cortisol assays, blood samples $(7 \mathrm{~mL})$ were taken via the jugular catheter at $-20,-10,15$, and 20 min relative to castration into tubes containing lithium heparin. All blood samples were placed on ice and centrifuged $(1,300 \times g)$ at $4^{\circ} \mathrm{C}$ for $10 \mathrm{~min}$ within $10 \mathrm{~min}$ of collection. Plasma was stored at $-80^{\circ} \mathrm{C}$ until it was assayed for concentrations of epinephrine, norepinephrine, and cortisol.

Cortisol was measured using a double-antibody RIA as described by Fisher et al. (2002). The minimum detectable level was $1.0 \mathrm{ng} / \mathrm{mL}$. The interassay coefficients of variation for plasma pools measuring 8.3, 24.4, and $63.4 \mathrm{ng} / \mathrm{mL}$ were $1.8,10.0$, and $5.8 \%$, respectively.

Catecholamine concentrations following castration procedures were measured in calves from the $\mathrm{C}$ and $\mathrm{SC}$ groups ( $\mathrm{n}=6 /$ treatment) and fewer samples were analyzed for the $\mathrm{C}$ group. To assay catecholamines, $20 \mu \mathrm{L}$ of $600 \mathrm{nmol} / \mathrm{L} N$-methyl dopamine internal standard was added to $1 \mathrm{~mL}$ of sample plasma and extracted on alumina. The alumina was washed with sodium bicarbonate solution, then water, and eluted with $0.2 M$ acetic acid. The extracted catecholamines were separated and measured by reverse phase-HPLC 
with electrochemical detection as described previously (Goldstein et al., 1981; Eisenhofer et al., 1986). The extraction efficiency for $\mathrm{N}$-methyl dopamine was $99.3 \%$.

\section{Statistical Analysis}

Repeated measures analyses were used to test for time by treatment interactions for maximum eye temperature, cortisol and catecholamine concentrations, HR, and HRV. Serial correlation was modeled with an autoregressive model and, where appropriate, a split plot ANOVA with Greenhouse-Geisser adjustment of degrees of freedom was fitted. Where there was a significant time by treatment interaction, repeated measures was followed by 1-way ANOVA to compare overall treatment differences before and after castration and the differences between treatments. Maximum eye temperature in the 20-min posttreatment period was compared with baseline (the mean of the 10 min before administration of local anesthetic). For HRV, time and frequency domain analysis of the 512 IBI (approximately $5 \mathrm{~min}$ ) posttreatment were compared with baseline (the 512 IBI before administration of local anesthetic). A log transformation was used before analysis of the frequency domain measures of HRV (HF, LF, and LF:HF ratio), and for these transformed variables the ratio of change $[\ln$ (before:after)] was used in the place of difference in the analyses described above. A log transformation was used before analysis of catecholamine concentrations. The HR profiles for 1 calf were not included because of high error rates in the data. Heart rate during local anesthetic injection and the 2 min posttreatment were compared with baseline. Results are presented as mean \pm standard error of the mean.

\section{RESULTS}

\section{Eye Temperature}

Eye temperature did not differ between treatments during the pretreatment period. Following time 0, there was no change with the LAC treatment, but all other treatments caused changes in eye temperature. During the first 2 min following castration in the SC treatment, there was a transient but nonsignificant decrease in eye temperature followed by a rapid increase (Figure 1). By 5 min after castration, eye temperature was greater than baseline for both castration treatments and stayed increased for the entire 20-min posttreatment observation period $(P<0.001)$. The increase was greater $(P$ $<0.05)$ in the SC calves compared with LASC calves $\left(+0.47 \pm 0.05^{\circ} \mathrm{C}\right.$ and $+0.28 \pm 0.05^{\circ} \mathrm{C}$, respectively $)$. Eye temperature increased posttreatment in $\mathrm{C}$ calves $\left(+0.10 \pm 0.05^{\circ} \mathrm{C} ; P<0.05\right)$, but the extent of this change was less than that following the castration treatments $(P<0.001)$.

\section{$H R$ and HRV}

During the 2 min following the injection of local anesthetic, HR increased above baseline $(P<0.001)$ by $6.4 \pm 1.4$ beats $/ \mathrm{min}(\mathbf{b p m})$ for LASC calves and $7.1 \pm$ $1.3 \mathrm{bpm}$ for LAC calves but did not change with sham administrations ( $\mathrm{C}$ and $\mathrm{SC}$ groups). The HR increased above baseline during the first 2 min following castration in LASC calves $(6.3 \pm 2.4 \mathrm{bmp} ; P<0.05)$ and SC calves $(15.3 \pm 2.8 \mathrm{bmp} ; P<0.001)$ and then declined rapidly to baseline levels (Figure 2). This increase in HR was greater $(P<0.05)$ following castration in SC calves compared with LASC calves. Posttreatment, the RMSSD was greater than during the baseline period for both treatments $(P<0.01)$, but more so without local anesthetic $(P<0.001$; Table 1$)$. Following castration in $\mathrm{SC}$ calves, HF increased $(P<0.05)$, whereas LF:HF ratio decreased $(P=0.05)$ from baseline. Following castration in LASC calves, LF decreased $(P=$ 0.05) compared with baseline. There were no changes in HR or any HRV measures following both $\mathrm{C}$ and LAC treatments.

\section{Plasma Cortisol and Catecholamine Concentrations}

Castration increased $(P<0.001)$ plasma cortisol concentrations (Figure 3), but more so in SC calves than in LASC calves $(P<0.05)$. There were no changes in cortisol concentrations in the $\mathrm{C}$ or LAC treatment groups.

Following castration in SC, plasma norepinephrine concentrations increased above baseline $(P<0.001)$ and reached peak concentrations by $2 \mathrm{~min}$, but had returned to baseline by 5.5 min after castration (Figure 4). Norepinephrine concentrations following castration in the SC treatment group were higher $(P<0.01)$ than in the $\mathrm{C}$ treatment group, for which concentrations did not differ from baseline. Plasma epinephrine concentrations increased above pretreatment levels $(P<0.05)$ following castration in the SC treatment, reached peak concentrations at $2 \mathrm{~min}$, and then returned to baseline levels by $3 \mathrm{~min}$ (Figure 5). Despite this increase, epinephrine concentrations in the SC treatment were not different from those in the $\mathrm{C}$ treatment at any time point.

\section{DISCUSSION}

The changes in eye temperature, the time and frequency domain measures of HRV, and the increase in cortisol and catecholamine concentrations in the cas- 


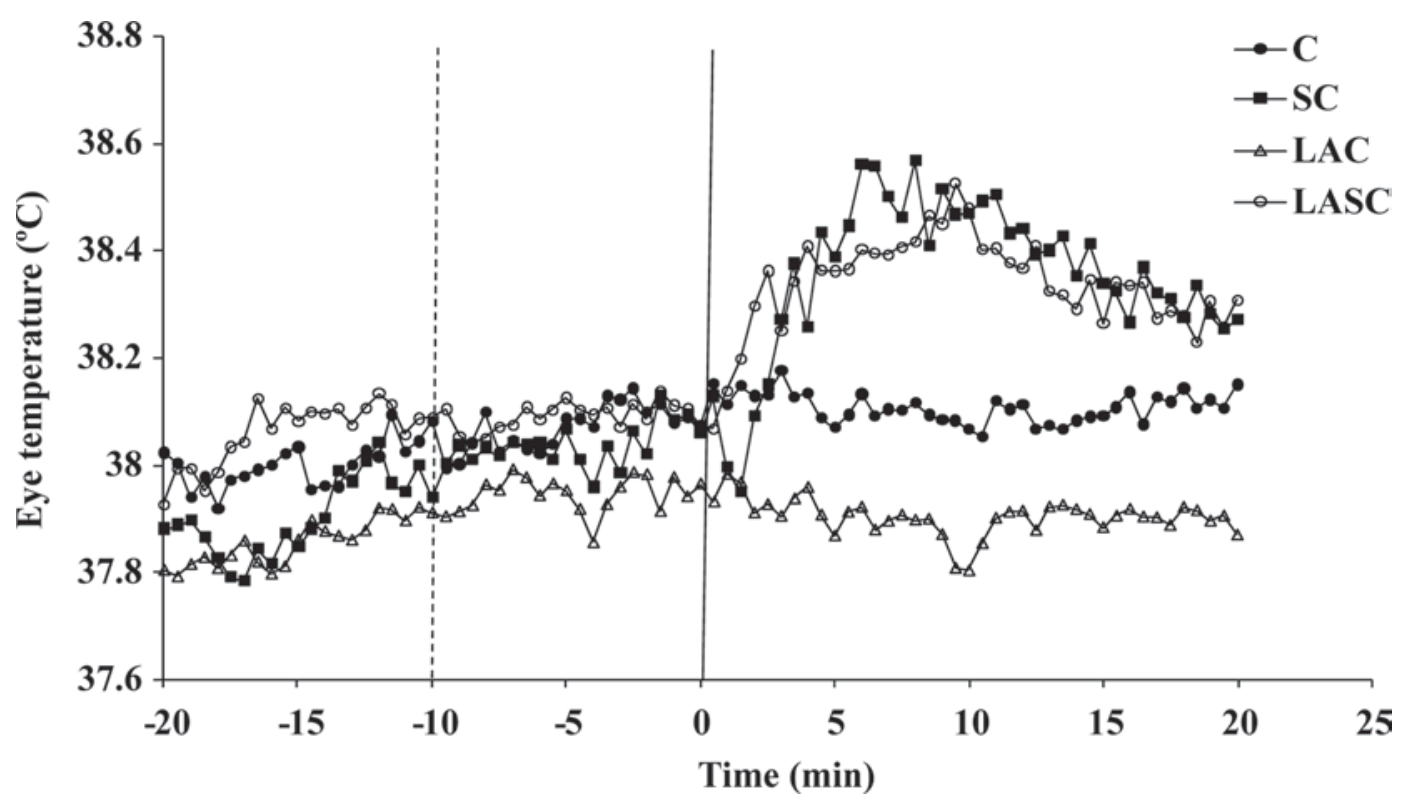

Figure 1. Maximum eye temperature $\left({ }^{\circ} \mathrm{C}\right)$ for control $(\mathrm{C} ; \mathrm{n}=8)$, castrated without local anesthetic $(\mathrm{SC} ; \mathrm{n}=6)$, local anesthetic control (LAC; $n=8$ ), and castrated with local anesthetic (LASC; $n=8)$ treatment groups. The dashed line indicates the time that local anesthetic or the sham procedure was administered and 0 min indicates the time of treatment.

trated animals indicate a response to the acute pain experienced with surgical castration. Local anesthesia reduced but did not completely eliminate these responses. The injection of local anesthetic caused HR to increase during the $2 \mathrm{~min}$ immediately following its administration, which suggests that this procedure may be stressful. Stafford et al. (2002) reported that administration of local anesthetic did not reduce the plasma cortisol response to surgical castration, but that this could be eliminated by using a combination of local anesthetic and a nonsteroidal antiinflammatory agent. Local anesthetic may not completely eliminate the pain of surgical castration because the extent of analgesia is limited to the testis and scrotal area, whereas stretch-

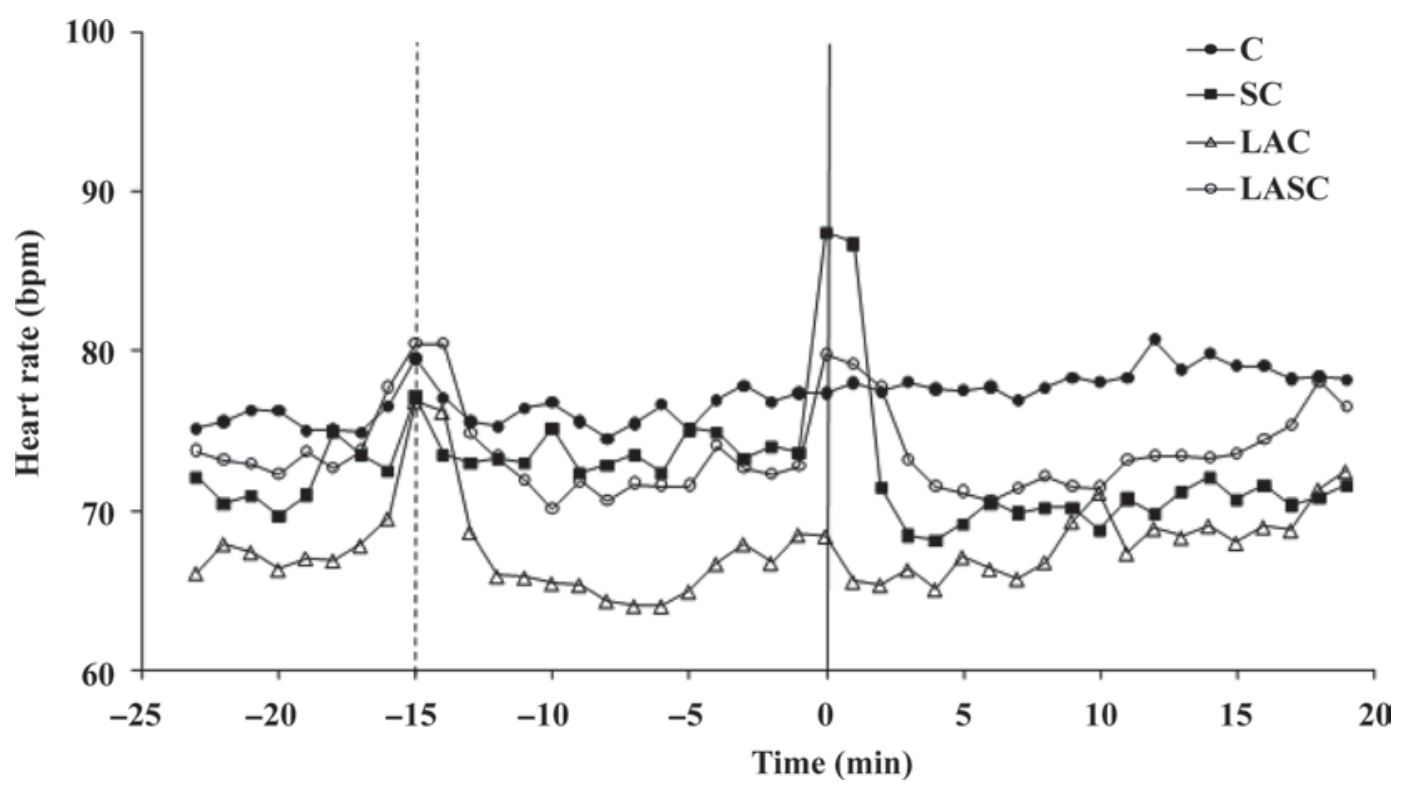

Figure 2. Mean heart rate (beats/min) for control $(\mathrm{C} ; \mathrm{n}=8)$, castrated without local anesthetic $(\mathrm{SC} ; \mathrm{n}=6)$, local anesthetic control (LAC; $\mathrm{n}=8$ ), and castrated with local anesthetic (LASC; $\mathrm{n}=7$ ) treatment groups. The dashed line indicates the time that local anesthetic or the sham procedure was administered and 0 min indicates the time of treatment. 


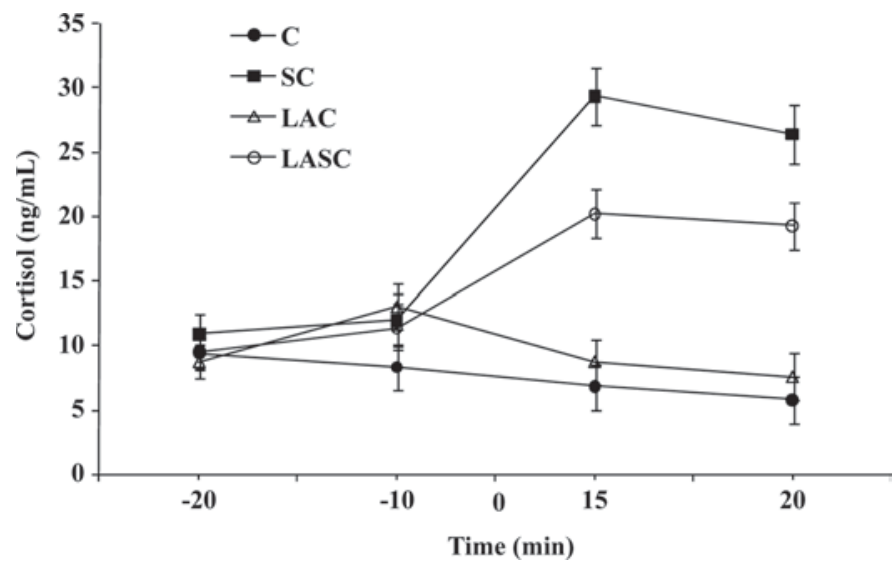

Figure 3. Mean cortisol concentration $(\mathrm{ng} / \mathrm{mL})$ for control $(\mathrm{C}: \mathrm{n}$ $=8)$, castrated without local anesthetic (SC; $\mathrm{n}=6)$, local anesthetic control (LAC; $\mathrm{n}=8$ ), and castrated with local anesthetic (LASC; $\mathrm{n}$ $=8$ ) treatment groups. Treatments were administered at 0 min. Error bars represent SEM.

ing and tearing of the spermatic cords would generate nociceptor impulses proximal to this in the peritoneal cavity (Stafford and Mellor, 2005b).

Eye temperature increased in calves in both castration treatments even though the changes were less marked in calves administered local anesthetic. This increase in eye temperature is consistent with observed responses to velvet antler removal in elk (Cook et al., 2005 ) and jugular catheterization of dairy cows (Stewart et al., 2007). Temperature increase was observed following cautery disbudding of calves (Stewart et al., 2008). The mechanism for the increase is still unknown; however, it was suggested that following disbudding, eye temperature changes were not attributable to heat (from the cautery iron), physical activity from struggling, increased HPA activity, or local inflammatory processes (Stewart et al., 2008). The present results provide further evidence of the change being mediated by the ANS; because no heat was applied, any induced inflammation would have been distant from the eye area and, although behavior was not recorded, calves did not struggle during or after the procedure. The adoption of an immobile stance following castration may function to avoid or reduce stimulation of hyperalgesic tissues, thereby reducing pain (Molony and Kent, 1997).

The increase in eye temperature may be associated with ANS-mediated vasodilation, and vasodilators released in response to pain may contribute. Endothelial cells in blood vessels can release nitric oxide to relax smooth muscle, resulting in vasodilation and increased blood flow. Other vasodilators such as epinephrine, prostaglandins, bradykinins, and histamine could be

Table 1. Mean $( \pm \mathrm{SEM})^{1}$ heart rate variability $(\mathrm{HRV})$ measures in time domain, the root mean square of successive differences (RMSSD), and frequency domain during baseline and the response in 4 treatment groups $^{2}$

\begin{tabular}{|c|c|c|c|c|c|}
\hline \multirow[b]{2}{*}{ HRV measure ${ }^{3}$} & \multicolumn{4}{|c|}{ Treatment ${ }^{4}$} & \multirow{2}{*}{$\begin{array}{l}P \text {-value, } \\
\text { ANOVA }\end{array}$} \\
\hline & $\mathrm{C}$ & $\mathrm{SC}$ & LAC & LASC & \\
\hline \multicolumn{6}{|l|}{ RMSSD (ms) } \\
\hline Baseline & $35.2 \pm 8.0$ & $31.3 \pm 13$ & $37.1 \pm 8.6$ & $47.1 \pm 10.1$ & NS \\
\hline Response & $32.9 \pm 7.6$ & $57.1 \pm 12.3$ & $33.3 \pm 8.1$ & $65.2 \pm 9.6$ & 0.043 \\
\hline$P$-value & NS & 0.001 & NS & 0.002 & 0.001 \\
\hline \multicolumn{6}{|l|}{ HF (nu) } \\
\hline Baseline & $36.9 \pm 4.9$ & $20.9 \pm 8.0$ & $35.8 \pm 5.3$ & $43.2 \pm 6.2$ & NS \\
\hline Response & $34.4 \pm 4.6$ & $31.8 \pm 7.5$ & $33.3 \pm 4.9$ & $53.3 \pm 5.8$ & NS \\
\hline$P$-value & NS & 0.020 & NS & NS & NS \\
\hline \multicolumn{6}{|l|}{ LF (nu) } \\
\hline Baseline & $63.1 \pm 4.9$ & $79.1 \pm 8.0$ & $64.2 \pm 5.3$ & $56.8 \pm 6.2$ & NS \\
\hline Response & $65.6 \pm 4.6$ & $68.2 \pm 7.5$ & $66.7 \pm 4.9$ & $46.7 \pm 5.8$ & 0.030 \\
\hline$P$-value & NS & NS & NS & 0.050 & NS \\
\hline \multicolumn{6}{|l|}{ LF:HF ratio } \\
\hline Baseline & $2.0 \pm 0.5$ & $4.9 \pm 0.8$ & $2.3 \pm 0.6$ & $1.5 \pm 0.7$ & NS \\
\hline Response & $2.3 \pm 0.5$ & $2.8 \pm 0.8$ & $2.5 \pm 0.5$ & $1.0 \pm 0.6$ & NS \\
\hline$P$-value & NS & 0.050 & NS & NS & NS \\
\hline
\end{tabular}

${ }^{1}$ Descriptive statistics are based on treatment means $( \pm \mathrm{SEM})$ of nontransformed data.

${ }^{2}$ Statistical significances for frequency domain measures (LF, HF, and the LF:HF ratio) are based on logtransformed data. $P$-values are based on results from the ANOVA. $P$-values within each row present differences pre versus post within treatment; the column of $P$-values presents comparisons across treatments.

${ }^{3} \mathrm{HF}=$ high frequency; $\mathrm{LF}=$ low frequency; nu = normalized units. Baseline $=$ the last 512 interbeat intervals before local anesthetic administration ; response $=$ the first 512 interbeat intervals posttreatment.

${ }^{4} \mathrm{C}=$ control $(\mathrm{n}=8) ; \mathrm{SC}=$ castrated without local anesthetic $(\mathrm{n}=3) ; \mathrm{LAC}=$ local anesthetic control $(\mathrm{n}=$ $7) ;$ LASC $=$ castrated with local anesthetic $(\mathrm{n}=5)$. 


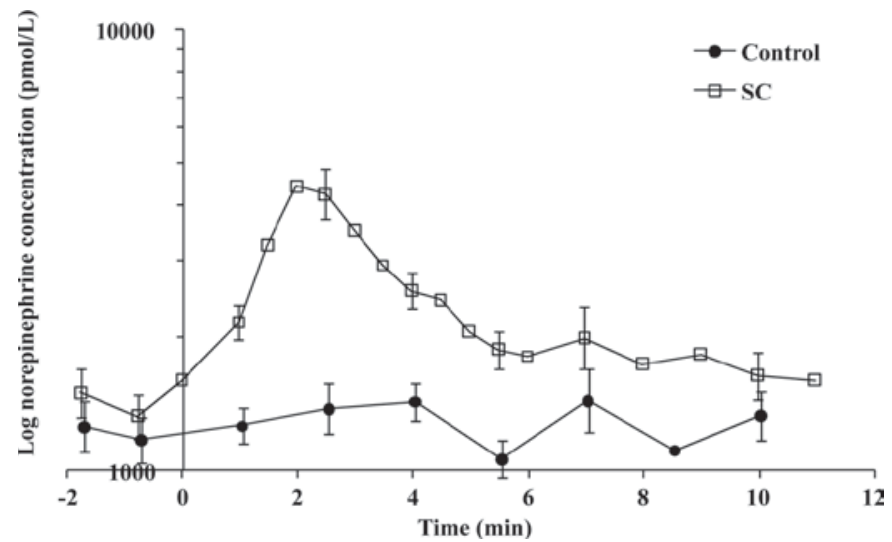

Figure 4. Norepinephrine concentrations following control $(\mathrm{n}=6)$ or castrated without local anesthetic $(\mathrm{SC} ; \mathrm{n}=6)$ treatments. Error bars represent SEM.

involved. Epinephrine increased in the present study and the other neurohumoral substances are released in association with pain (Mellor et al., 2000).

There was a peak in HR during the 2 min after castration, which was blocked by administration of local anesthetic. This acute HR response coincided with peak plasma catecholamine concentrations, which suggests a transient increase in sympathetic activity that may be associated with the initial pain of the scrotal incision, mediated from higher centers of the nervous system. Lay et al. (1992a) reported that epinephrine and HR responses coincided following hot iron branding. Following the initial response to castration without local anesthetic, there was a rapid decrease in HR, a decrease in LF:HF ratio, and an increase in RMSSD and HF power, indicating an increase in parasympathetic activity (Kleiger et al., 1995). Few studies measured HR during castration; however, decreases were reported with surgical castration of calves (Schwartzkopf-Genswein et al., 2005) and ring castration of sheep (Johnson et al., 2005). An increase in parasympathetic tone may be associated with deep visceral pain, as would occur when the spermatic cords are torn (King, 1987). The parasympathetic nervous system acts to counteract sympathetic activity by lowering cardiac output and blood pressure by vasodilation. This could explain the increase in eye temperature. Experimental studies involving pharmacological inhibition or stimulation of ANS activity, such as with atropine sulfate (a parasympathetic tone blockade), atenolol (a sympathetic tone blockade), and isoproterenol (a sympathetic stimulant) would be required to investigate this further.

Plasma catecholamines have a short half-life of 1 to 2 min (Hjemdahl, 1993), and few studies have measured them in cattle within seconds of a painful husbandry procedure. In the present study, the acute increase in catecholamine concentrations indicated stimulation of the SNS in response to the pain associated with castration. Baseline plasma catecholamine concentrations support those reported in cattle by Lefcourt and Elsasser (1995) and Locatelli et al. (1989) but were lower than values reported by Lay et al. (1992a,b). Consistent with the rapid response time in the present study, plasma epinephrine peaked at $30 \mathrm{~s}$ after hot iron branding (Lay et al., 1992a), and concentrations of both epinephrine and norepinephrine peaked by $30 \mathrm{~s}$, then returned to baseline within 5 min following electrical stunning of sheep (Lowe et al., 2000). Mellor et al. (2002) reported that norepinephrine concentrations peaked at $30 \mathrm{~min}$ and epinephrine at $5 \mathrm{~min}$ following dehorning of calves; however, given the short plasma half-life of catecholamines, the acute responses to dehorning may have been overlooked because the first blood sample was not taken until 5 min posttreatment. In the present study, catecholamine concentrations had returned to baseline by around 5 min posttreatment. The effect of castration was more marked on plasma concentrations of norepinephrine than on epinephrine, which suggests the increased sympathetic activity was predominantly attributable to peripheral sympathetic neural stimulation associated with tearing of the spermatic cords (Ahmed et al., 1994).

In conclusion, there was evidence that local anesthetic may have alleviated some of the pain caused by castration because it reduced rather than eliminated changes in eye temperature, HR, HRV, and plasma cortisol concentrations. Increases in the catecholamine release and HR responses within the first 2 min following castration without local anesthetic suggest a short-lived initial sympathetic response. The underlying physiological basis of the increase in eye temperature is still not fully elucidated but appears to be associated with parasympathetic activity. This work has shown that infrared thermography, HR, and HRV can complement

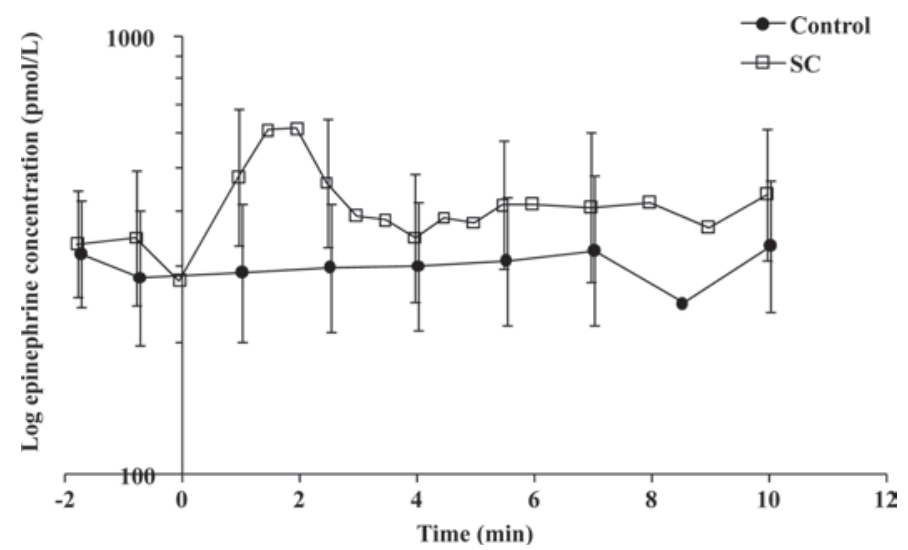

Figure 5. Epinephrine concentrations following control $(n=6)$ or castrated without local anesthetic $(\mathrm{SC} ; \mathrm{n}=6)$ treatments. Error bars represent SEM. 
each other as noninvasive measures of ANS activity in cattle and that they can be used to assess acute pain responses and pain alleviation.

\section{ACKNOWLEDGMENTS}

The authors thank AgResearch staff Kate Clark, Gemma Worth, Andrea Rogers, and Frankie Huddart, and DairyNZ staff Peter Gore and Kate Watkins for their valuable technical assistance; Neil Cox (AgResearch) for assistance with the statistical analysis, and the AgResearch farm staff. This research was funded by the Foundation for Research, Science and Technology (Wellington, New Zealand).

\section{REFERENCES}

Ahmed, M. W., A. H. Kadish, M. A. Parker, and J. J. Goldberger. 1994. Effect of physiologic and pharmacologic adrenergic stimulation on heart rate variability. J. Am. Coll. Cardiol. 24:1082-1090.

Cook, N. J., J. S. Church, A. L. Schaefer, J. R. Webster, L. R. Matthews, and J. M. Suttie. 2005. Stress and pain assessment of velvet antler removal from Elk (Cervus elaphus canadensis) and Reindeer (Rangifer tarandus). Online J. Vet. Res. 9:13-25.

Eisenhofer, G., D. S. Goldstein, R. Stull, H. R. Keiser, T. Sunderland, D. L. Murphy, and I. J. Kopin. 1986. Simultaneous liquidchromatographic determination of 3,4-dihydroxyphenylglycol, catecholamines, and 3,4-dihydroxyphenylalanine in plasma, and their responses to inhibition of monoamine oxidase. Clin. Chem. 32:2030-2033.

Fisher, A. D., M. A. Crowe, M. E. Alonso de la Varga, and W. J. Enright. 1996. Effect of castration method and the provision of local anesthesia on plasma cortisol, scrotal circumference, growth, and feed intake of bull calves. J. Anim. Sci. 74:2336-2343.

Fisher, A. D., G. A. Verkerk, C. J. Morrow, and L. R. Matthews. 2002. The effects of feed restriction and lying deprivation on pituitary-adrenal axis regulation in lactating cows. Livest. Prod. Sci. 73:255-263.

Goldstein, D. S., G. Feuerstein, J. L. Izzo Jr., I. J. Kopin, and H. R. Keiser. 1981. Validity and reliability of liquid chromatography with electrochemical detection for measuring plasma levels of norepinephrine and epinephrine in man. Life Sci. 28:467-475.

Hjemdahl, P. 1993. Plasma catecholamines-Analytical challenges and physiological limitations. Baillieres Clin. Endocrinol. Metab. 7:307-353.

Johnson, C. B., K. J. Stafford, S. P. Sylvester, R. N. Ward, S. Mitchinson, and D. J. Mellor. 2005. Effects of age on the electroencephalographic response to castration in lambs anaesthetised using halothane in oxygen. N. Z. Vet. J. 53:433-437.

King, A. S. 1987. Physiological and Clinical Anatomy of the Domestic Mammals. Vol. 1. Central Nervous System. Oxford University Press, Oxford, UK.

Kleiger, R. E., P. K. Stein, M. S. Bosner, and J. N. Rottman. 1995. Time-domain measurements of heart rate variability. Pages 33-45 in Heart Rate Variability. M. Malik and A. J. Camm, ed. Futura Publishing Co., Armonk, New York.

Lay, D. C., T. H. Friend, K. K. Grissom, C. L. Bowers, and M. E. Mal. 1992a. Effects of freeze or hot-iron branding of Angus calves on some physiological and behavioural indicators of stress. Appl. Anim. Behav. Sci. 33:137-147.

Lay, D. C., T. H. Friend, R. D. Randel, C. L. Bowers, K. K. Grissom, and O. C. Jenkins. 1992b. Behavioral and physiological effects of freeze or hot-iron branding on crossbred cattle. J. Anim. Sci. 70:330-336.

Lefcourt, A. M., and T. H. Elsasser. 1995. Adrenal responses of Angus $\times$ Hereford cattle to the stress of weaning. J. Anim. Sci. 73:26692676 .
Locatelli, A., P. Sartorelli, F. Agnes, G. P. Bondiolotti, and G. B. Picotti. 1989. Adrenal response in the calf to repeated simulated transport. Br. Vet. J. 145:517-522.

Lowe, T. E., A. Velarde, C. Devine, S. R. Payne, and N. G. Gregory. 2000. Validation of urinary catecholamines as a stress indicator following electric stunning. Pages $144-145$ in Proc. 46th International Congress of Meat Science and Technology, Buenos Aires, Argentina.

Marchant-Forde, R. M., D. J. Marlin, and J. N. Marchant-Forde. 2004. Validation of a cardiac monitor for measuring heart rate variability in adult female pigs: Accuracy, artefacts and editing. Physiol. Behav. 80:449-458.

Mellor, D. J., C. J. Cook, and K. J. Stafford. 2000. Quantifying some responses to pain as a stressor. Pages 171-198 in The Biology of Animal Stress: Basic Principles and Implications for Animal Welfare. G. P. Moberg and J. A. Mench, ed. CABI Publishing, Wallingford, UK.

Mellor, D. J., K. J. Stafford, S. E. Todd, T. E. Lowe, N. G. Gregory, R A. Bruce, and R. N. Ward. 2002. A comparison of catecholamine and cortisol responses of young lambs and calves to painful husbandry procedures. Aust. Vet. J. 80:228-233.

Molony, V., and J. E. Kent. 1997. Assessment of acute pain in farm animals using behavioral and physiological measurements. J. Anim. Sci. 75:266-272.

Molony, V., J. E. Kent, and I. S. Robertson. 1995. Assessment of acute and chronic pain after different methods of castration of calves. Appl. Anim. Behav. Sci. 46:33-48.

Niskanen, J. P., M. P. Tarvainen, P. O. Ranta-Aho, and P. A. Karjalainen. 2004. Software for advanced HRV analysis. Comput. Methods Programs Biomed. 76:73-81.

Parrott, R. F., B. H. Misson, and C. F. de la Riva. 1994. Differential stressor effects on the concentrations of cortisol, prolactin and catecholamines in the blood of sheep. Res. Vet. Sci. 56:234-239.

Schwartzkopf-Genswein, K. S., M. E. Booth-McLean, T. A. McAllister, and G. J. Mears. 2005. Physiological and behavioural changes in Holstein calves during and after dehorning or castration. Can. J. Anim. Sci. 85:131-138.

Stafford, K. J., and D. J. Mellor. 2005a. Dehorning and disbudding distress and its alleviation in calves. Vet. J. 169:337-349.

Stafford, K. J., and D. J. Mellor. 2005b. The welfare significance of the castration of cattle: A review. N. Z. Vet. J. 53:271-278.

Stafford, K. J., D. J. Mellor, S. E. Todd, R. A. Bruce, and R. N. Ward. 2002. Effects of local anaesthesia or local anaesthesia plus a nonsteroidal anti-inflammatory drug on the acute cortisol response of calves to five different methods of castration. Res. Vet. Sci. 73:61-70.

Stewart, M., K. J. Stafford, S. K. Dowling, A. L. Schaefer, and J. R. Webster. 2008. Eye temperature and heart rate variability of calves disbudded with or without local anaesthetic. Physiol. Behav. 93:789-797.

Stewart, M., J. M. Stookey, K. J. Stafford, C. B. Tucker, A. R. Rogers, S. K. Dowling, G. A. Verkerk, A. L. Schaefer, and J. R. Webster. 2009. Effects of local anesthetic and a nonsteroidal antiinflammatory drug on pain responses of dairy calves to hotiron dehorning. J. Dairy Sci. 92:1512-1519.

Stewart, M., J. R. Webster, G. A. Verkerk, A. L. Schaefer, J. J. Colyn, and K. J. Stafford. 2007. Non-invasive measurement of stress in dairy cows using infrared thermography. Physiol. Behav. 92:520525.

Task Force of the European Society of Cardiology and the North American Society of Pacing and Electrophysiology. 1996. Heart rate variability: Standards of measurement, physiological interpretation and clinical use. Circulation 93:1043-1065.

von Borell, E., J. Langbein, G. Despres, S. Hansen, C. Leterrier, J. Marchant-Forde, R. Marchant-Forde, M. Minero, E. Mohr, A. Prunier, D. Valance, and I. Veissier. 2007. Heart rate variability as a measure of autonomic regulation of cardiac activity for assessing stress and welfare in farm animals-A review. Physiol. Behav. 92:293-316.

Weaver, A. D., G. St. Jean, and A. Steiner. 2005. Bovine Surgery and Lameness. Blackwell Publishing Ltd, Oxford, UK. 